TAO, Vol. 15, No. 4, 697-711, November 2004

\title{
Assessment of Traffic Contribution to Hydrocarbons Using 2,2-Dimethylbutane as a Vehicular Indicator
}

\author{
Chih-Chung Chang ${ }^{1, *}$, Tai-Yih Chen $^{1}$, Clock Chou ${ }^{1}$, Shaw-Chen Liu ${ }^{1}$
}

(Manuscript received 14 November 2003, in final form 13 October 2004)

\begin{abstract}
This study investigated the feasibility of using 2,2-dimethylbutane (22DMC4) as an unambiguous indicator for traffic emissions, and applied it to assess traffic contribution to individual hydrocarbons in an atmospheric environment. The concept involves using concentration ratios of individual non-methane hydrocarbons (NMHCs) to 22DMC4, which are characteristic of traffic emissions to reveal excess concentration contributed by nontraffic sources.

Air samples from three collections were analyzed for 22DMC4 and other NMHCs simultaneously to examine ratios of NMHCs/22DMC4. Two sample collections were made at different traffic transportation links in Kaohsiung City, and high concentration correlation was observed between 22DMC4 and most NMHCs for samples collected during heavy traffic hours. The third collection was made in the great Kaohsiung metropolitan area for comparison of NMHCs/22DMC4 ratios in different environments. Ratios of toluene/22DMC4 and ethene/22DMC4 obtained from the third collection were significantly greater than those from the two roadside collections in Kaohsiung City, suggesting other sources existed in addition to traffic.

Comparing the NMHCs/22DMC4 ratios observed in a given area with the values obtained from pure traffic emissions as a reference can provide a quick diagnosis for non-traffic contributions. Another merit of using NMHCs/22DMC4 ratios of atmospheric components is to provide a basis of normalization, so that direct comparison of emission profiles collected in different times and places is possible.
\end{abstract}

(Key words: 2,2-dimethylbutane; Non-methane hydrocarbons; Traffic emissions)

\footnotetext{
${ }^{1}$ Research Center for Environmental Changes, Academia Sinica, Taipei, Taiwan, ROC

* Corresponding author address: Dr. Chih-Chung Chang, Research Center for Environmental Changes, Academia Sinica, Taipei, Taiwan, ROC;E-mail: joechang@rcec.sinica.edu.tw
} 


\section{INTRODUCTION}

Sources of non-methane hydrocarbons (NMHCs) in an environment may include mobile vehicles, industrial plants, household, biological activities, and so on. NMHCs have various reactive potentials with respect to ozone formation (Carter and Atkinson 1989; Carter 1994), and successful smog abatement programs require measuring data of ozone precursors to identify effective species forming ozone in a given area. Furthermore, appropriate methods to apportion their sources for crafting control strategies are also needed for reducing surface ozone. In a business orientated metropolitan area, exhaust and evaporative emissions from vehicles are the major sources of the NMHCs. Other minor but numerous municipal sources (e.g., leakage from liquefied petroleum gases (LPG), natural gas (NG), dry cleaning, incinerators, etc.) are also non-negligible (Wang et al. 2000). The study of apportionment of NMHCs to various sources and its implicated control strategies have been conducted using chemical mass balance (CMB) receptor models (Vega et al. 2000; Abu-Allaban et al. 2002), provided that their major sources have been clearly characterized. However, in an industrial type metropolitan area, major sources of NMHCs may be the result of both vehicular emissions and various industrial sources whose constituents are usually complex and variable (Na et al. 2001; Chang et al. 2003). Owing to components and component proportions of these sources are variable constantly, emission profiles of these sources are difficult to determine. In these circumstances, the CMB receptor model is not an effective tool for source apportionment of NMHCs. For species commonly found in industrial cities, such as toluene, ethene, ethylbenzene, xylene, nbutane, propane, etc., their relative abundances were significantly different from the traffic signature, suggesting the existence of non-vehicular emissions ( $\mathrm{Na}$ et al. 2001; Chang et al. 2003). In principle, the contribution of the non-vehicular sources can be determined, if a compound exclusive to vehicular emissions exists which can serve as an indicator of vehicular emissions and basis for calculating the relative abundance with other species. Comparing individual NMHC/indicator ratio observed in a given area with the values obtained from pure traffic emissions can provide a quick diagnosis for non-traffic contributions of individual NMHCs in a given area.

Two basic criteria for being a traffic indicator are: (1) emission being traffic exclusivity, (2) there exists certain robust correlation with other compounds in traffic emissions. 2,2-dimethylbutane (22DMC4) seems to meet these criteria. Like methyl tert-butyl ether (MTBE), 22DMC4 is added to gasoline as an octane enhancer, and there exists few other industrial applications. Except for some minor leakage from gasoline refilling processes and refinery activities, exhaust and evaporative emission from vehicles are the most important sources of 22DMC4 found in an atmospheric environment (NTP 2001; U.S. EPA 2002), and such exclusivity reveals 22DMC4 have potential as an indicator of traffic emissions. The concept of employing 22DMC4 as a traffic emission reference can be potentially valuable at the policy-making level, because the method provides a simple means to partition the relative environmental impact on air quality from traffic and non-traffic contributions for individual NMHCs. 


\section{EXPERIMENTAL METHODS}

\subsection{Instrumental Conditions}

Ambient air samples were collected in 0.5-liter flasks and emission profiles of traffic sources were collected in 2-liter stainless steel canisters (provided by University of California, Irvine). All flasks and canisters were evacuated and humidified prior to sample collection. Each aliquot of $403 \mathrm{ml}$ from flasks was drawn to the cryogenic trap packed with fine glass beads cooled at liquid nitrogen temperature for enrichment. During injection, the trap was heated with boiling water and a stream of high purity $\mathrm{H}_{2}$ flushed the trapped NMHCs onto the columns. The analytical system consisted of two gas chromatographs (GC) with two flame ionization detectors (Hewlett-Packard 6890) for analyzing $\mathrm{C}_{2}-\mathrm{C}_{10}$. Two capillary columns, a PLOT (Chrompack; $30 \mathrm{~m} \times 0.53 \mathrm{~mm} ; \mathrm{d}_{\mathrm{f}}=15.0 \mu \mathrm{m}$ ) and a DB-1 (J\&W; $60 \mathrm{~m} \times 0.32 \mathrm{~mm}$; $d_{f}=1.0 \mu \mathrm{m}$ ), were connected in parallel by a Y-splitter with $91 \%$ flow entering the PLOT column. The PLOT column was used for separation of $\mathrm{C}_{2}-\mathrm{C}_{5}$ hydrocarbons, and the oven temperature program was initially held at $-20^{\circ} \mathrm{C}$ for $1.5 \mathrm{~min}$, then ramped to $180^{\circ} \mathrm{C}$ at

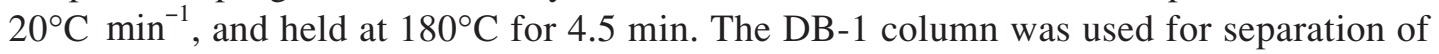
$22 \mathrm{DMC} 4$ and $\mathrm{C}_{5}-\mathrm{C}_{10}$ hydrocarbons, and the oven temperature was initially held at $-50^{\circ} \mathrm{C}$ for 1.5 minutes, then ramped to $30^{\circ} \mathrm{C}$ at $18^{\circ} \mathrm{C} \mathrm{min}^{-1}$, to $145^{\circ} \mathrm{C}$ at $13^{\circ} \mathrm{C} \mathrm{min}^{-1}$, to $200^{\circ} \mathrm{C}$ at $25^{\circ} \mathrm{C} \mathrm{min}^{-1}$. A $30 \mathrm{~L}$ pontoon was pressurized to 100 psi with ambient air using an oil-free bellows pump to serve as a working standard. This working standard was used to monitor and back-correct any possible instrumental drift and to assure data quality, which was analyzed in between every 4 samples.

\subsection{Field Mission}

Three sample collections were made to evaluate the applicability of an traffic emission reference based on 22DMC4. Two collections, hereafter referred to as Collection I and Collection II, were made on two separate occasions in Kaohsiung City where traffic emissions appeared to be the dominant sources of NMHCs, and no major factories or gasoline stations are known to exist nearby. These two collections were considered to be representative of a comprehensive mixture of different vehicle types. Figure 1 shows locations (marked as open circles) of Collection I, and Collection II in Kaohsiung City (refer to Table 1 for sampling conditions). To test and verify the applicability of an emission reference based on 22DMC4, Collection III (144 samples) was made in the great Kaohsiung metropolitan area which has a population over 2 million. Two field trips were conducted to collect samples at 9:30 a.m. and 11:30 a.m. during Oct. 10 - 13 and Oct. 25 - 28, 2002 at nine Taiwan EPA monitoring stations (marked as solid circles). 


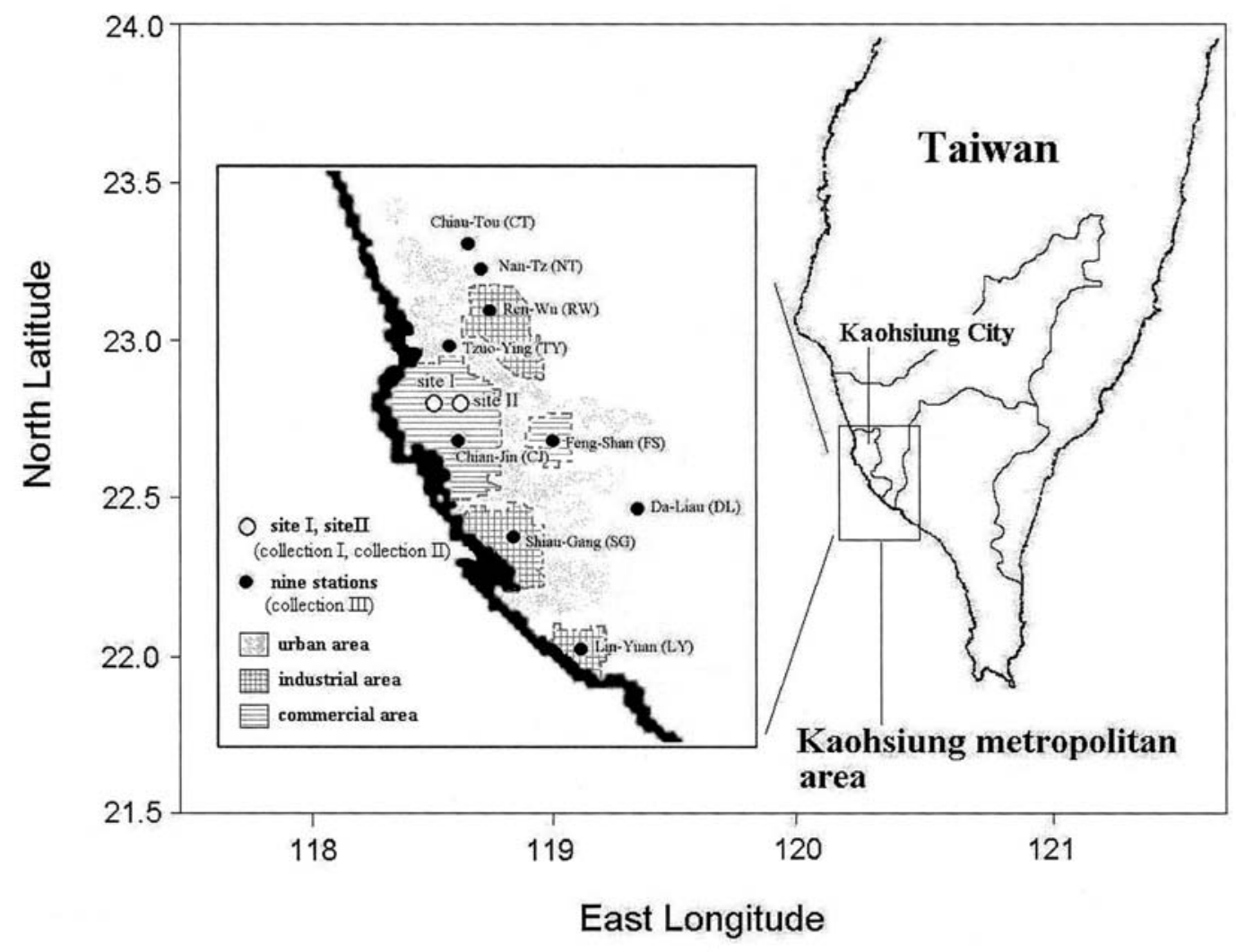

Fig. 1. Positions of the three collections in Kaohsiung City (labeled as site I, site II) and the great Kaohsiung metropolitan area (labeled as Collection III).

Table 1. Description of sampling conditions for three collections.

\begin{tabular}{lllll}
\hline City & Sampling label & Sampling site & Sampling date & Description \\
\hline Kaohsiung City & Collection I & Site I & Apr. 15-162003 & $\begin{array}{l}\text { 12 samples were collected in 2-h intervals for a } \\
\text { period of 24 hours for observing a possible } \\
\text { diurnal cycle. }\end{array}$ \\
\cline { 2 - 5 } & Collection II & Site II & Apr. 152003 & $\begin{array}{l}\text { 4 samples were collected in the evening rush } \\
\text { hours. }\end{array}$ \\
\hline $\begin{array}{l}\text { Kaohsiung } \\
\text { industrial } \\
\text { metropolitan area }\end{array}$ & Collection III & $\begin{array}{l}\text { nine Taiwan EPA } \\
\text { monitoring } \\
\text { stations }\end{array}$ & $\begin{array}{l}\text { Oct. 10 13 and } \\
\text { Oct. 25-28 2002 }\end{array}$ & $\begin{array}{l}144 \text { samples at nine Taiwan EPA monitoring } \\
\text { stations were collected in daytime. }\end{array}$ \\
\hline
\end{tabular}




\section{RESULTS AND DISCUSSIONS}

\subsection{DMC4 as Traffic Indicator}

22DMC4, having a high octane number (Research Octane Number: 94), is a gasoline additive produced from hexane conversion. It has been used to replace hexane (Research Octane Number: 31 ) to enhance the octane level of gasoline. Except for some minor leakage from gas stations during pumping and refinery processes, the presence of 22DMC4 in ambient air is almost exclusively from vehicle emissions. Many studies find that ratios and correlations between different VOC species can be useful in identifying VOC emission sources (Gee and Sollars 1998; Chan et al. 2002; Sweet et al. 1998; Gelencser et al. 1997). While ratios of NMHCs to compounds such as ethyne, benzene, xylenes, etc. instead of 22DMC4 may also exhibit consistent results in urban environments as these compounds are also mainly released from tailpipes in areas where traffic is the dominant source, however they can be of multisources and non-exclusive to traffic in different environments in which the industrial emissions can be the significant contributors (Liu et al. 2000). Therefore, compared to most other NMHCs, the exclusivity of 22DMC4 makes it a more suitable reference compound for indicating traffic emissions. The concentrations of some selected species measured from Collection I over a period of 24 hours are shown in Fig. 2. A double-peak feature is clearly shown, which is characteristic of a typical traffic pattern (Liu et al. 2000). Ethene, benzene, toluene, ethylbenzene, and xylene (BTEX) are the typical compounds found in car exhaust (Chang et al. 2001; Gamas et al. 1999). During rush hour, 7 a.m. - 9 a.m. and 6 p.m. - 8 p.m., increased

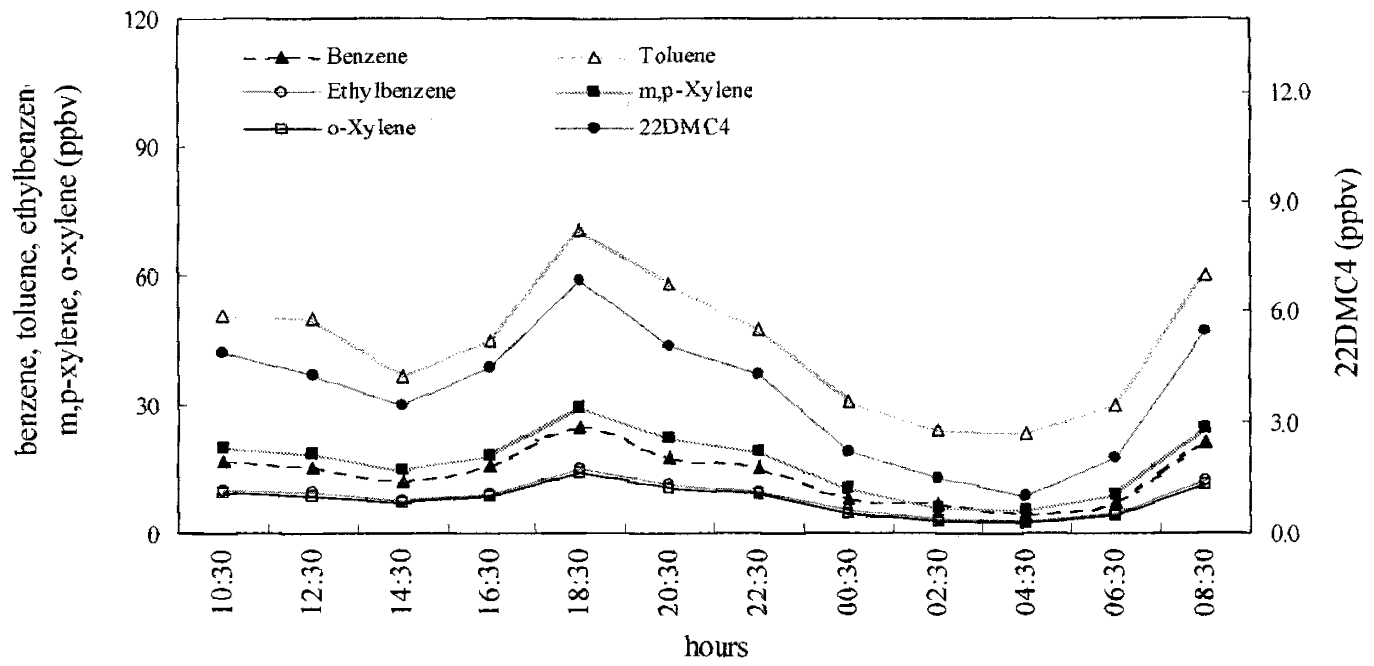

Fig. 2. Concentration variation of selected NMHCs at a road-site location (i.e., site I collection). Samples were collected every two hours during a weekday. 
concentration was obvious for these compounds, which declined in the off-peak hours. Figure 3 shows relative correlations of these compounds with 22DMC4. Although significant concentration variation was observed during a day, most compounds were highly correlated with 22DMC4 for all samples with $\mathrm{R}^{2}$ greater than 0.90 , strongly suggesting that these compounds were of a common origin, namely the traffic. 22DMC4 is a general component in gasolinepowered vehicle emissions; however, it is close to nil in the exhaust of diesel, and LPG vehicles. The proportion of diesel and LPG vehicles among all vehicles in Kaohsiung metropolitan area are less than $3 \%$ and $1 \%$, respectively. Therefore, their influence on NMHCs/22DMC4 ratios should be insignificant. In addition, such good correlation between 22DMC4 and NMHCs in the emission profile of traffic sources suggests that the air was rather well mixed and the difference between components of these vehicles is smeared by the mixing.
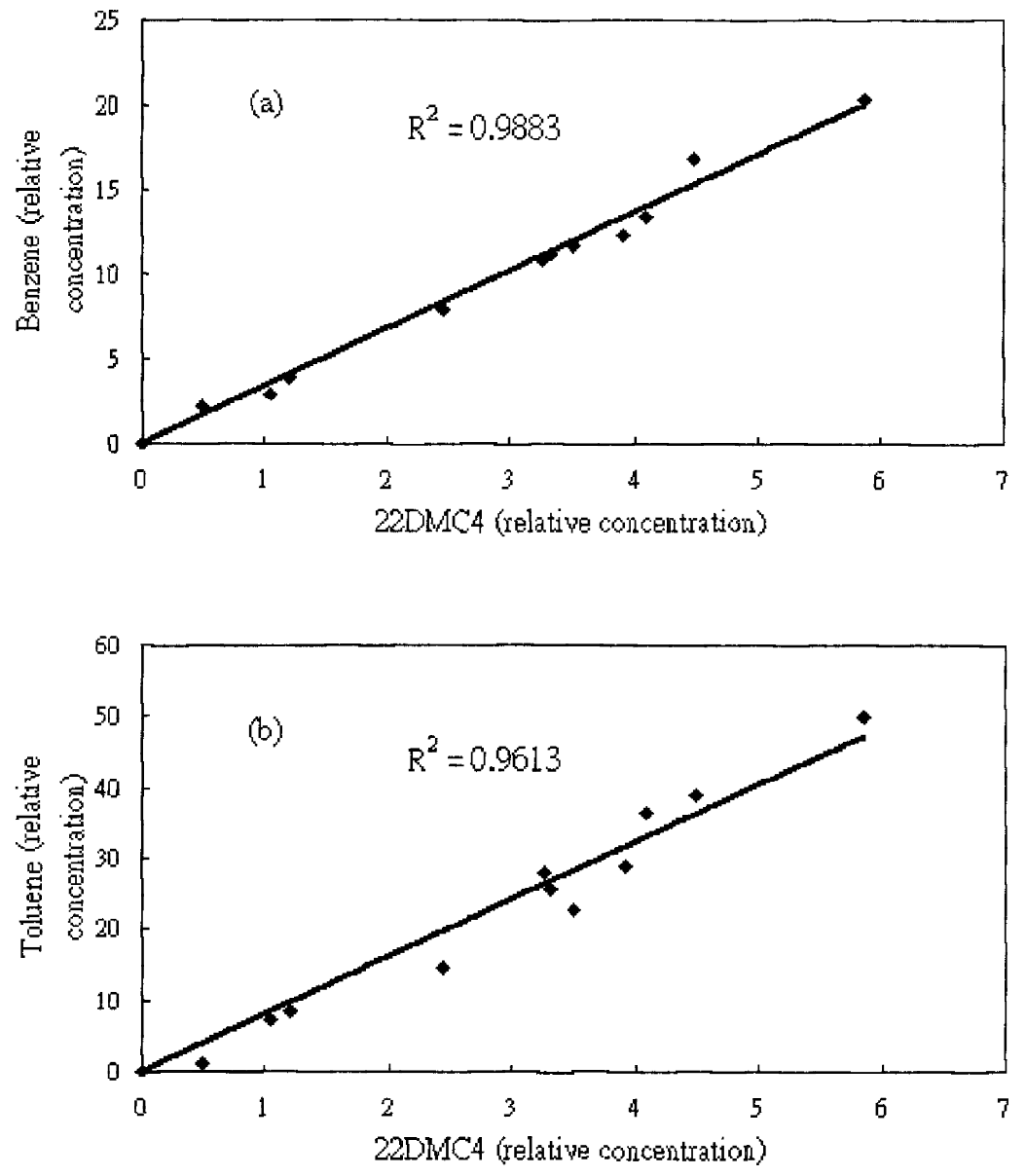

Fig. 3. Relative correlations of selected NMHCs with 22DMC4, (a) benzene; (b) toluene; (c) ethylbenzene; and (d) m,p-xylene (i.e., site I collection). 

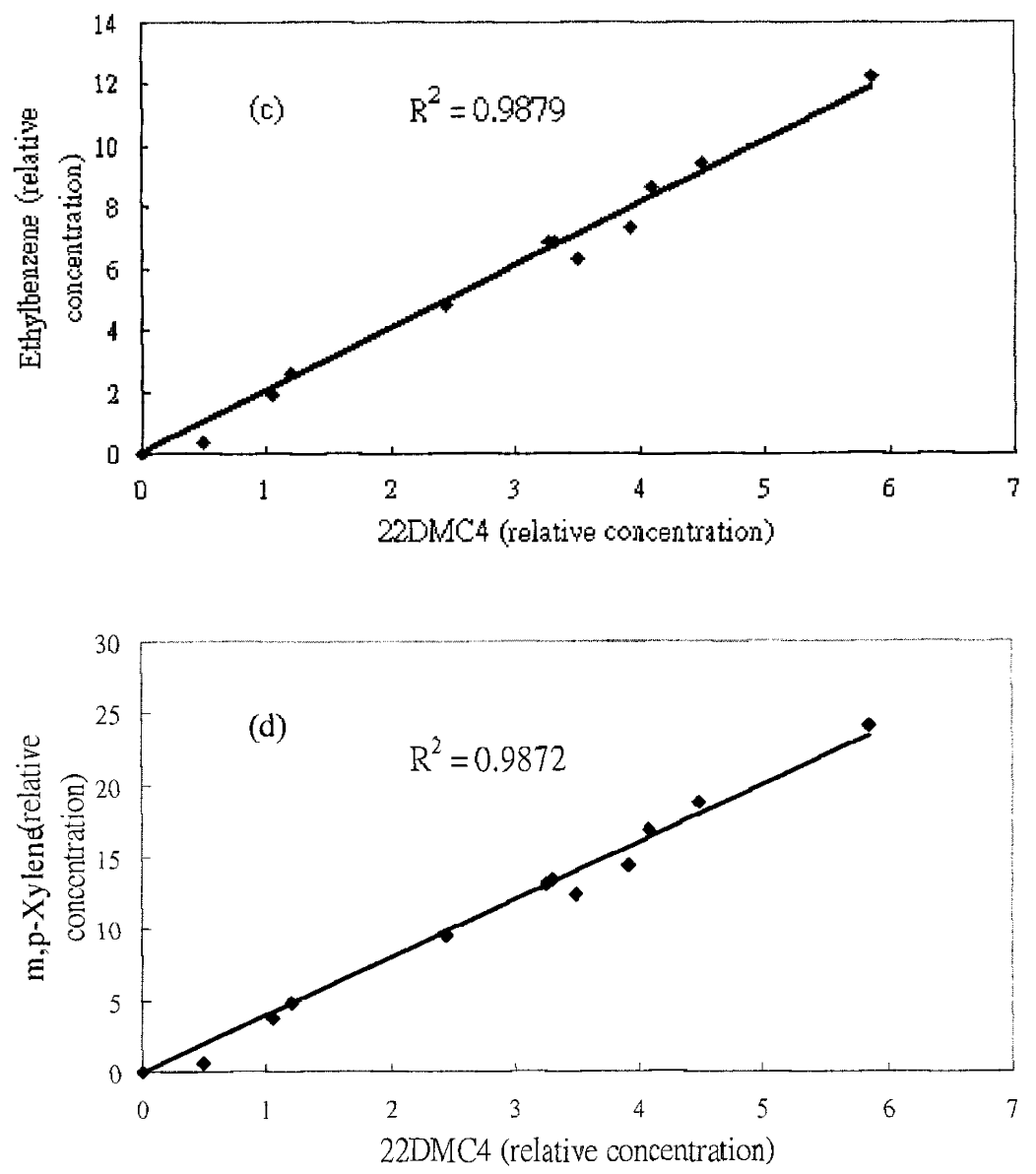

(Fig. 3. continued)

To build up NMHCs/22DMC4 ratios representative of emission characteristic of traffic sources, ratios of individual NMHCs to 22DMC4 during a day were expected to show selfconsistency. However, it was found that certain nighttime samples deviated noticeably from daytime samples for toluene and n-butane. Figure 4 shows concentration ratios of some selected NMHCs to 22DMC4 for a period of 24 hours, the values of ethylbenzene/22DMC4, $\mathrm{m}, \mathrm{p}$-xylene/22DMC4 and o-xylene/22DMC4 were rather constant during the day, but toluene/22DMC4 and n-butane/22DMC4 of some samples increased at late night when the traffic was light. Two possible causes might have induced such variation. One is the difference in removal rate between individual NMHCs and 22DMC4, the other is interference from nontraffic sources. In daytime, the intensity of traffic emissions in an urban area can overwhelm the chemical sink. As a result, the change of NMHCs/22DMC4 by the sink may be masked by the sources. During low traffic hours at night, when traffic flow subsided, the effect of sink 


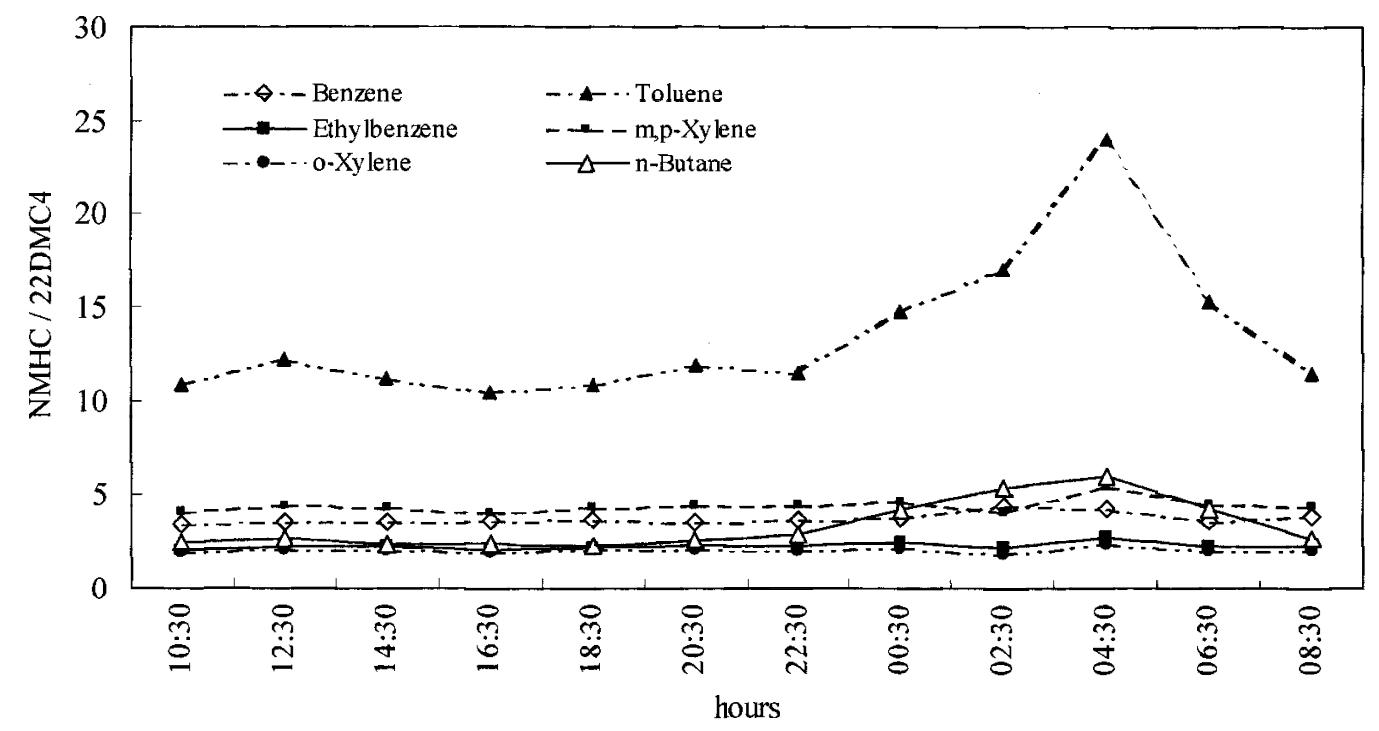

Fig. 4. Concentration ratios of selected NMHCs to 22DMC4 for site I samples.

may then become more accentuated. The possible sinks for 22DMC4 are chemical reactions with oxidizing radicals and physical removal such as wet deposition. In Table 2, Henry's law constant and solubility as well as reaction rate constant with $\mathrm{HO}$ radicals are listed for illustrating the strength of physical and chemical sinks for various species. 22DMC4's wet deposition rate is believed to be lower than BTEX based on the difference in solubility or Henry's law constants. If the influence of different wet deposition rates for a remote effect is significant, the ratios of BTEX to 22DMC4 should decrease at late night. Nevertheless, ethylbenzene/22DMC4, m,p-xylene/22DMC4 and o-xylene/22DMC4 ratios were rather constant throughout the day, which implies the influence of wet deposition on NMHCs/22DMC4 was insignificant, and the increased ratios of toluene/22DMC4 and n-butane/22DMC4 at late night may have been due to other causes. NMHC's nighttime chemistry due to reactions with for example $\mathrm{NO}_{3}$ could be different from daytime chemistry in which reactions with $\mathrm{OH}$ radicals tends to dominate the first step of NMHC oxidation processes (Atkinson et al. 1984; Atkinson 1990). In fact, rate constants of NMHCs reacting with $\mathrm{NO}_{3}$ are about 3 - 4 orders of magnitude smaller than when they react with $\mathrm{OH}$ radicals in daytime. At night, the lifetimes of most $\mathrm{NMHC}$ reacting with $\mathrm{NO}_{3}$ are more than several months, thus the role of removal in controlling NMHC concentrations and ratios is not obvious. Hence, it is prudent to consider other possibilities. Even though traffic appeared to be the dominant source of NMHCs and no major factories or gasoline stations are known to exist near the sampling sites, it is difficult to avoid the possibility of minor emissions from non-traffic sources. During rush hour, traffic sources dominate emissions, and emissions from non-traffic sources are relatively unobvious; therefore, the influence of non-traffic sources 
over NMHCs/22DMC4 ratios is very little. In off-peak hours, traffic emissions are small, and the relative influence of non-traffic sources on NMHCs/22DMC4 ratios is accentuated. This increased contribution from non-traffic sources significantly influences the ratios of toluene/22DMC4 and n-butane/22DMC4. Given this possibility, uniform NMHCs/22DMC4 ratios occurring during rush hour were chosen to represent characteristic ratios of traffic sources.

Table 2. Atmospheric lifetimes and solubility for various VOCs.

\begin{tabular}{|c|c|c|c|c|c|c|c|}
\hline Compound & benzene & toluene & ethylbenzene & m,p-xylene & o-xylene & n-butane & 22DMC4 \\
\hline $\begin{array}{l}\text { Henry's law const. } \\
\text { (atm·L/mol) at } 25^{\circ} \mathrm{C}\end{array}$ & 0.23 & 0.27 & 0.34 & 0.32 & 0.21 & 0.95 & $N / A^{d}$ \\
\hline $\begin{array}{l}\text { Solubility }(\mathrm{mg} / \mathrm{L})^{a} \\
\text { at } 25^{\circ} \mathrm{C} ; \text { in } \mathrm{H}_{2} \mathrm{O}\end{array}$ & 1,770 & 530 & 160 & $160-180$ & 170 & 61 & 18 \\
\hline$k_{\mathrm{OH}} \times 10^{12 \mathrm{~b}}$ & 1.23 & 5.96 & 6.96 & 21.7 & 14.7 & 2.54 & 2.23 \\
\hline Lifetime (day) & 9.7 & 2.0 & 1.7 & 0.27 & 0.41 & 4.7 & 5.4 \\
\hline
\end{tabular}

a. Handbook of chemistry and physicals, $75^{\text {th }}$ ed.

b. Atkinson. R (1990).

c. For a 12-h daytime average $\mathrm{OH}$ radical concentration of $1.94 \times 10^{6}$ molecule $\mathrm{cm}^{-3}$, Prinn et al. (1995).

d. N/A denotes not available.

To validate whether the ratios of individual NMHCs to 22DMC4 obtained from Collection I are typical and representative of the traffic dominated urban environment. A second sample collection was made at another urban site (Collection II) during evening rush hours. Similar results were noticed that the ratios of NMHCs to 22DMC4 for Collection I and Collection II are highly consistent (e.g., ethene/22DMC4 $=18.9 \pm 3.1$ and $20.2 \pm 4.2$; benzene/22DMC4 $=3.6 \pm 0.3$ and $3.4 \pm 0.8$; toluene/22DMC4 $=11.7 \pm 3.9$ and $14.0 \pm 2.5$; ethylbenzene $/ 22 \mathrm{DMC} 4=2.2 \pm 0.2$ and $2.2 \pm 0.2 ; \mathrm{m}, \mathrm{p}$-xylene $/ 22 \mathrm{DMC} 4=4.3 \pm 0.4$ and $4.0 \pm 0.4 ;$ o-xylene/22DMC4 $=1.9 \pm 0.2$ and $2.0 \pm 0.2$ ), suggesting that the concept of using $\mathrm{NMHCs} / 22 \mathrm{DMC} 4$ ratios are practically sound, if the environment is dominated by similar vehicular emissions. The consistency between the two collections although is not surprising, it leads to an implication that the ratios of individual NMHCs to 22DMC4 obtained in traffic dominant environments may serve as a gauge to readily reveal the excess concentration contributed by non-traffic sources in a given area. These two collections (Collection I, II) in Kaohsiung city were regarded as emission profiles of traffic sources in the Kaohsiung metropolitan area.

In addition to 22DMC4, gasoline-additive MTBE is also a suitable vehicular indicator (Chang et al. 2003). Except for some minor leakage from gas stations during pumping, the presence of MTBE in ambient air is almost exclusively from vehicular emissions (Vance 1998). Nevertheless, MTBE has a tendency to easily co-elute with other neighboring eluting com- 
pounds in gas-chromatography/flame ionization detectors (GC/FID). Shown in Fig. 5 is a chromatogram of the 22DMC4 and MTBE for a typical urban air sample measured by the GC/FID system. It was noted that MTBE and 2,3-dimethylbutane were partially co-eluted in the chromatograms of ambient samples, and the quantification of MTBE would have to be done by elaborate mass spectrometry (MS). The characteristic peak of MTBE at m/z 73 was used in the quantitative analysis to avoid interference from 2,3-dimethylbutane or other nearby compounds. In contrast to MTBE analysis, 22DMC4 has no interference problems in GC/FID analyses, and it can be easily analyzed using a more popular detector, i.e., FID, due to its low cost and complexity, avoiding the use of costly MS.

\subsection{Field Studies}

In areas where multiple sources of NMHCs exist, the concentration ratio of most NMHCs to 22DMC4 should be greater than the base values set by the pure traffic condition, as the contribution of NMHCs from the multiple sources is superimposed upon the traffic emissions, whereas the source of 22DMC4 is almost singularly from traffic. To illustrate this additive effect, a field mission was performed in $18 \times 28 \mathrm{~km}^{2}$ area located at nine stations in the Kaohsiung metropolitan area (Collection III) known for its numerous industries and factories. In overview, this collection of 144 samples at nine stations presented rather poor correlation

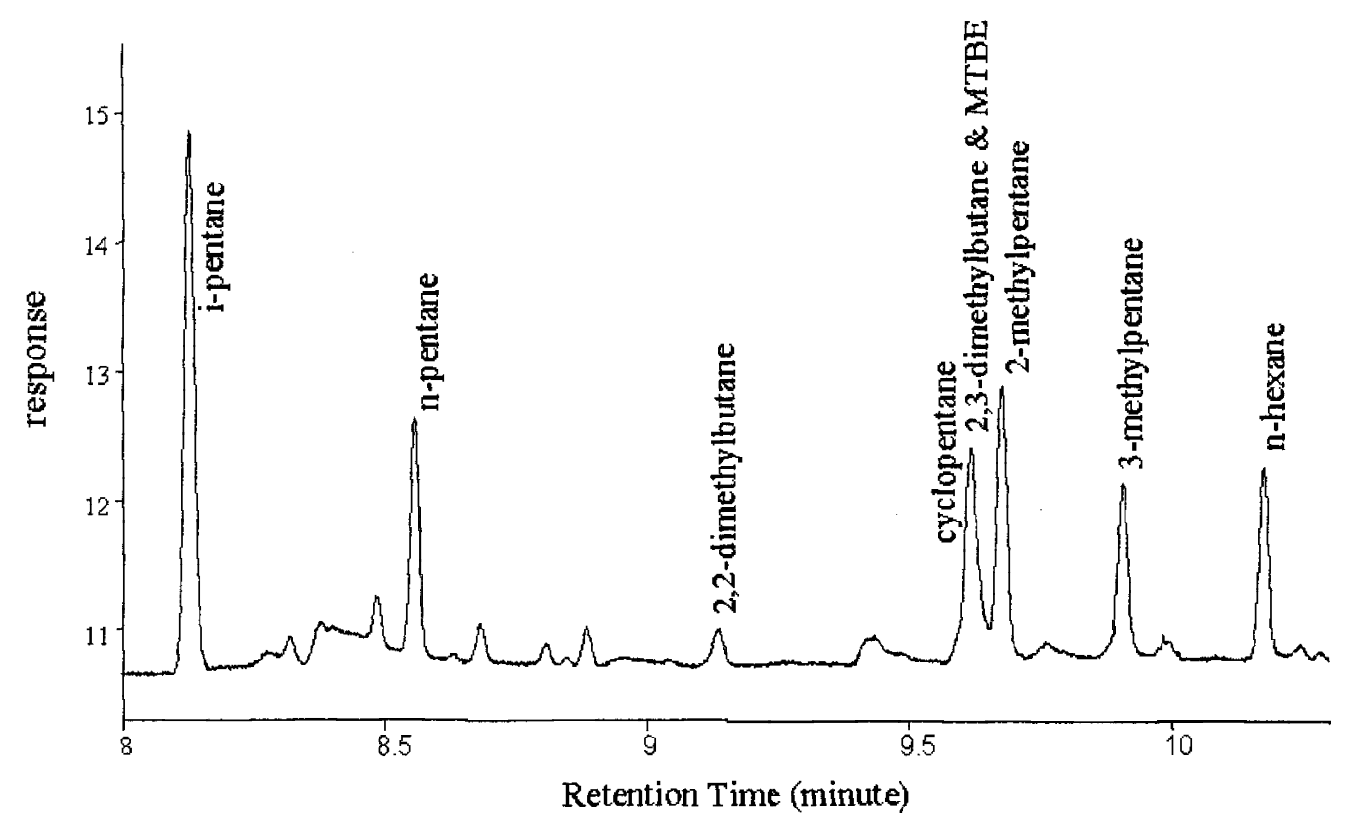

Fig. 5. GC/FID/DB-1 chromatogram of a typical urban air sample for segment of $\mathrm{C}_{5}-\mathrm{C}_{6}$ hydrocarbons. 
among ethene, propene, $\mathrm{n}$-butane, benzene, toluene, and ethylbenzene with $\mathrm{R}^{2}$ ranging from 0.0204 to 0.4777 , which is in contrast to the urban collection (Collection I) mentioned above with $\mathrm{R}^{2}$ greater than 0.9 , suggesting that many of these species had various sources other than traffic. In this collection, alkenes and alkanes such as ethene, propene, 1-butene, propane and n-butane as well as aromatics such as toluene exhibited substantially higher concentration proportions among all measured species than normally would have been seen in a typical urban environment. These are the typical refinery or cracking plant products used as starting reagents or raw materiel for other industries near-by. The concentrations of some of these compounds is plotted versus 22DMC4 in Fig. 6, superimposed by the regression line obtained from Collection I samples for comparison. The degree of concentration in excess of these NMHCs can be clearly seen by reference to the regression line of Collection I samples from the pure traffic environment.
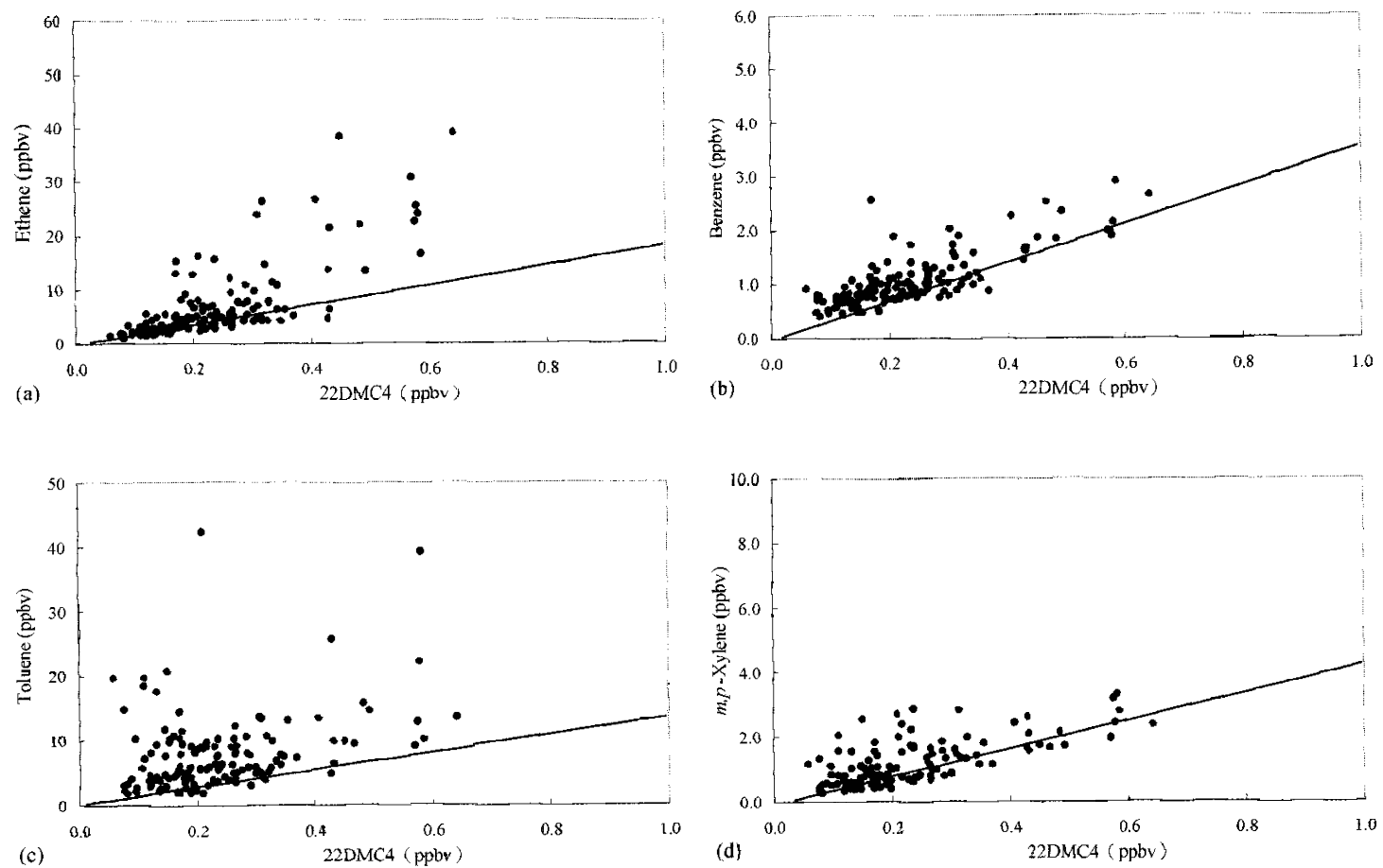

Fig. 6. Concentrations of (a) ethene; (b) benzene; (c) toluene; and (d) m,p-xylene versus 22DMC4 for Collection III in Kaohsiung industrial metropolitan area as shown by the solid circles. Superimposed is the regression line fitting to the Collection I (straight line) to display the concentration excess to pure traffic condition with $\mathrm{R}^{2}=0.9296$ for (a); $\mathrm{R}^{2}=0.9883$ for (b); $\mathrm{R}^{2}=0.9613$ for (c); $\mathrm{R}^{2}=0.9872$ for (d). 
In this collection, concentrations of toluene and ethene were highest in the Kaohsiung metropolitan area. These compounds with high photochemical activities and concentrations were considered the major factors causing secondary air pollution in this area. Shown in Table 3 are average concentrations of toluene, ethene and benzene at nine stations in Kaohsiung metropolitan area (Collection III) and two traffic occasions (Collection I, II), together with these species to 22DMC4 ratios. The average ratio of toluene/22DMC4 (after subtracting respective background values of toluene and 22DMC4 in the atmosphere) in the Kaohsiung metropolitan area during the investigating periods was 39.6, and this value was 3.1 times toluene/22DMC4 ratio of the traffic sources. In other words, it was estimated that about $68 \%$ of toluene was emitted and/or leaked from non-traffic sources with the remaining $32 \%$ attributed to traffic sources. The toluene/22DMC4 ratios at all nine stations were obviously higher than the ratios of two traffic occasions. Such result illustrates that excess toluene from non-traffic sources in the Kaohsiung metropolitan area is significant. The upper-left corner in Fig. 6 indicates that concentrations of toluene in some samples were relatively high, and toluene/22DMC4 was significantly greater than toluene/22DMC4 of traffic sources. These samples are collected at the LY and CJ stations where located nearby the major industrial parks in the Kaohsiung metropolitan area (see Fig. 1 for station locations). The ratios of toluene/22DMC4 in these two stations were 75.4 and 50.9, and these values were 5.8 and 3.9 times that of the traffic sources. Such a result illustrates that toluene emissions near these two stations had significantly higher per-

Table 3. Concentrations of ethane, benzene and toluene and their ratios to 22DMC4 at nine stations (Collection III) and two rush hour traffic periods (Collection I and II).

\begin{tabular}{|c|c|c|c|c|c|c|c|}
\hline \multirow[b]{2}{*}{ Collection } & \multirow[b]{2}{*}{ Station } & \multicolumn{2}{|c|}{ Ethene } & \multicolumn{2}{|c|}{ Benzene } & \multicolumn{2}{|c|}{ Toluene } \\
\hline & & $\begin{array}{l}\text { Concentration } \\
\text { (ppbv) }\end{array}$ & Ethene/22DMC4 & $\begin{array}{l}\text { Concentration } \\
\text { (ppbv) }\end{array}$ & Benzene/22DMC4 & $\begin{array}{l}\text { Concentration } \\
(\mathrm{ppbv})\end{array}$ & Iolucne/22DMC4 \\
\hline \multirow[t]{9}{*}{ Collection III } & Shiaul-Gang (SG) & $5.7 \pm 2.3$ & $25.6 \pm 7.8$ & $1.0 \pm 0.3$ & $4.3 \pm 0.9$ & $7.6 \pm 2.9$ & $40.6 \pm 26.0$ \\
\hline & Tzuo-Ying (TY) & $6.8 \pm 7.5$ & $22.7 \pm 8.5$ & $1.1 \pm 0.4$ & $4.7 \pm 1.2$ & $8.3 \pm 6.2$ & $36.7 \pm 31.0$ \\
\hline & Chian-Jin (CJ) & $9.8 \pm 8.1$ & $31.4 \pm 13.5$ & $1.3 \pm 0.3$ & $4.9 \pm 1.2$ & 13.1 上 10.5 & $50.9 \pm 43.8$ \\
\hline & Nan-Te (NT) & $7.4 \pm 8.2$ & $30.3 \pm 17.2$ & $1.1 \pm 0.7$ & $5.7 \pm 3.1$ & $5.0 \pm 3.5$ & $29.7 \pm 19.6$ \\
\hline & Da-Liau (DL) & $5.8 \pm 4.1$ & $29.0 \pm 17.6$ & $1.1 \pm 0.4$ & $5.4 \pm 1.6$ & $7.2 \pm 3.3$ & $33.6 \pm 13.7$ \\
\hline & Ren-Wu (RW) & $14.1 \pm 26.0$ & $44.5 \pm 52.1$ & $1.0 \pm 0.6$ & $5.1 \pm 1.4$ & $5.9 \pm 3.0$ & $29.3 \pm 10.7$ \\
\hline & Lin-Yuan (LY) & $8.0 \pm 6.3$ & $37.6 \pm 23.1$ & $1.1 \pm 0.3$ & $6.2 \pm 3.3$ & $10.4 \pm 10.4$ & $75.4 \pm 97.3$ \\
\hline & Feng-Shan (FS) & $11.4 \pm 1.8$ & $28.0 \pm 17.8$ & $1.6 \pm 0.7$ & $3.9 \pm 0.9$ & $9.1 \pm 3.9$ & $25.8 \pm 11.7$ \\
\hline & Chiau-Tou (CT) & $4.5 \pm 10.7$ & $25.5 \pm 10.8$ & $0.8 \pm 0.6$ & $4.9 \pm 1.5$ & $5.3 \pm 2.8$ & $32.5 \pm 18.3$ \\
\hline Collection I & Site I & & $18.9 \pm 3.1$ & & $3.6 \pm 0.3$ & & $11.7 \pm 3.9$ \\
\hline Collection II & Site 11 & & $20.2 \pm 4.2$ & & $3.4 \pm 0.8$ & & $14.0+2.5$ \\
\hline
\end{tabular}


centages from non-traffic sources. Therefore, Figure 6 not only provides the degree of influence from non-traffic sources for toluene, but also the areas where non-traffic emissions are noticeable.

In addition to LY and CJ stations, stations SG and TY also had high toluene/22DMC4 ratios. However, the average concentrations of toluene at these two stations were only 7.6 and 8.3 ppbv, and the values were smaller than those at the LY and CJ stations (10.4 ppbv and $13.1 \mathrm{ppbv}$ ). This indicates that even though toluene emissions from non-traffic sources near these two stations exhibit relatively high proportions, the emission scales seem smaller than the LY and CJ stations. At these four stations (LY, CJ, SG, TY), not only were the toluene/22DMC4 ratios high, but the variability in ratios was very large, this phenomenon is consistent with emissions from non-traffic sources which are not time dependent.

Ethene is a major starting reagent in plastics synthesis. Except for pipeline evaporative emissions from factories, it also comes from incomplete combustion in vehicles. The average ratio of ethene/22DMC4 (after subtracting respective background values of ethene and 22DMC4) in the Kaohsiung metropolitan area was 1.9 times that of traffic sources; hence, it was estimated that about $48 \%$ of ethene emitted and/or leaked from non-traffic sources. About half of the ethene contribution in the air at the RW and LY stations, located at petrochemical industry and plastic industry parks, was estimated to come from non-traffic emissions, and variation in the ethane to 22DMC4 ratios at these two stations was also large. Furthermore, concentrations of ethene at the RW station were the highest among all nine stations suggesting that upwind of this station or a neighboring area was a significant region of non-traffic emissions.

Although the photochemical reactivity of benzene is very low (Table 2), benzene is a recognized carcinogen and toxic. Fortunately, the concentration of benzene in industrial areas over recent years has been low compared to that of other major hydrocarbons (Hsieh et al. 2003; Na et al. 2001), and concentrations of benzene in this collection were also low (Table 3). Besides, Figure 6 reveals that emissions of benzene from non-traffic sources were relatively small, suggesting benzene's major source to be traffic emissions. The average benzene/22DMC4 ratio (after subtracting respective background values) in the Kaohsiung metropolitan area was 1.4 times that of traffic sources. It was estimated that about $29 \%$ of benzene was emitted or/ and leaked from non-traffic sources, with the remainder attributed to traffic sources.

The concentrations of all three compounds (ethene, benzene, toluene) at the FS station (located in commercial area) were noticeably high relative to most other stations. However, ethene/22DMC4, benzene/22DMC4 and toluene/22DMC4 were lower than the others, indicating that the traffic emissions of NMHCs were relatively large, and conversely, emission proportion from non-traffic sources near this station was less significant than in other areas.

\section{CONCLUSIONS}

The purposes of this study were to evaluate the applicability of a traffic emission reference based on 22DMC4 and to apply the proposed method to assess traffic contribution to individual hydrocarbons in the Kaohsiung metropolitan area. Ratios of ethene/22DMC4 and toluene/22DMC4 obtained from the Kaohsiung metropolitan area were significantly greater 
than those from the two roadside collections in Kaohsiung City suggesting multiple sources in addition to traffic. The results show that some species such as toluene and ethene emitted from non-traffic sources are significant in the Kaohsiung metropolitan area during the sampling periods. By comparing the NMHCs/22DMC4 ratios observed in a given area with traffic reference values can quickly diagnose the significance of non-traffic emissions. Such a concept of using 22DMC4 as an exclusive indicator of traffic emissions offers a convenient check on traffic and non-traffic contributions to ambient NMHCs, facilitating a control strategy for planning reductions in surface ozone.

Acknowledgements The author would like to thank the personnel who participated in air sampling and analysis. This research was supported in part by Taiwan EPA under contract number: EPA-91-FA11-03-A062.

\section{REFERENCES}

Abu-Allaban, M., A. W. Gertler, and D. H. Lowenthal, 2002: A preliminary apportionment of the sources of ambient PM10, PM2.5, and VOCs in Cairo. Atmos. Environ., 36, 55495557.

Atkinson, R., 1990: Gas-phase tropospheric chemistry of organic compounds: a review.Atmos. Environ., 24, 1-42.

Atkinson, R., C. N. Plum, W. P. L. Carter, A. M. Winer, and Jr, J. N. Pitts, 1984: Rate constants for the gas phase reactions of $\mathrm{NO}_{3}$ radicals with a series of organics in air at $295 \pm 1^{\circ}$ K. J. Phys. Chem., 88, 1210.

Carter, W. P. L., 1994: Development of ozone reactivity scales for volatile organic compounds. J. Air Waste Manag. Assoc., 44, 881-899.

Carter, W. P. L., and R. Atkinson, 1989: Computer modeling study of incremental hydrocarbon reactivity. Environ. Sci. Technol., 23, 864-880.

Chan, C. Y., L. Y. Chan, X. M. Wang, Y. M. Liu, S. C. Lee, S. C. Zou, G. Y. Sheng, and J. M. Fu, 2002: Volatile organic compounds in roadside microenvironments of metropolitan Hong Kong. Atmos. Environ., 36, 2039-2047.

Chang, C. C., J. G. Lo, and J. L. Wang, 2001: Assessment of reducing ozone forming potential for vehicles using liquefied petroleum gas as an alternate fuel.Atmos. Environ., 35, 6201-6211.

Chang, C. C., S. J. Lo, J. G. Lo, and J. L.Wang, 2003: Analysis of methyl tert-butyl ether (MTBE) in the atmosphere and implications as an exclusive indicator of automobile exhaust. Atmos. Environ., 37, 4747-4755.

Dragos, D., 2000: Comparison of the properties and behavior of MTBE and the fuel oxygenates TAME, ETBE, DIPE, TBA, and ethanol, National Groundwater Association, San Francisco, March 17, 2000.

Gamas, E. D, L. Diaz, R. Rodriguez, E. Lopez-Salinas, and I. Schifter, 1999: Exhaust emissions from gasoline- and LPG-powered vehicles operating at the altitude of Mexico City. J. Air Waste Manag. Assoc., 49, 1179-1189. 
Grosjean, E., R. A. Rasmuseen, and D. Grosjean, 1998: Ambient levels of gas phase pollution in Porto Alegre, Brazil. Atmos. Environ., 32, 3371-3379.

Gelencser, A., K. Siszler, and J. Hlavay, 1997: Toluene-benzene concentration ratio as a tool for characterizing the distance from vehicular emission sources. Environ. Sci. Technol., 31, 2869-2872.

Howard, P. H., 1991: Handbook of environmental degradation rates, Lewis Publishers, Chelsea, Michigan.

Hsieh, C. C., and J. H. Tsai, 2003: VOC concentration characteristics in Southern Taiwan. Chemosphere, 50, 545-556.

Liu, C., Z. Xu, Y. Du, and H. Guo, 2000: Analyses of volatile organic compounds concentrations and variation trends in the air of Changchun, the northeast of China. Atmos. Environ., 34, 4459-4466.

Na, K., Y. P. Kim, K. C. Moon, I. Moon, and K. Fung, 2001: Concentrations of volatile organic compounds in an industrial area of Korea. Atmos. Environ., 35, 2747-2756.

National Toxicology Program (NTP). "NTP CHEMICAL REPOSITORY- 2,2DIMETHYLBUTANE." 13 August 2001. National Toxicology Program Chemical Repository. 14 April 2003. http://ntp-server.niehs.nih.gov/

Prinn, R. G., R. F. Weiss, B. R. Miller, J. Huang, F. N. Alyea, D. M. Cunnold, P. J. Fraser, D. E. Hartley, and P. G. Simmonds, 1995: Atmospheric trends and lifetime of CH3CCl3 and global $\mathrm{OH}$ concentrations. Science, 269, 187-191.

Sweet, C. W., and S. J. Vertmette, 1992: Toxic volatile organic compounds in urban air in Illinois. Environ. Sci. Technol., 26, 165-173.

U.S. Environmental Protection Agency. "2,2-DIMETHYLBUTANE" 5 November 2002. Technology Transfer Network, Clearinghouse for Inventories \& Emission Factors, Speciate 3.2. 1 May 2003. http://www.epa.gov/ttn/chief/software/speciate/

Vance, D. B., 1998: MTBE: Character in Question. Environ. Technol., 8, 1-12.

Vega, E., V. Mugica, R. Carmona, and E. Valencia, 2000: Hydrocarbon source apportionment in Mexico City using the chemical balance receptor model. Atmos. Environ., 34, 4121-4129.

Wang, J. L., W. H. Ding, and T. Y. Chen, 2000: Source determination of light non-methane hydrocarbons by simultaneous multi-site sampling in a metropolitan area.Chemosphere, 2, 11-22. 